\title{
Computer-assisted evaluation of anaerobic biodegradation products
}

\author{
Gilles Klopman, ${ }^{1 *}$ Roustem Saiakhov, ${ }^{1}$ Meihua Tu, ${ }^{1}$ Florin Pusca ${ }^{1}$ and Emiel Rorije ${ }^{2}$ \\ ${ }^{\prime}$ Chemistry Department, Case Western Reserve University, 10700 Euclid Avenue, \\ Cleveland, OH 44106, USA \\ ${ }^{2}$ Laboratory for Ecotoxicology, National Institute for Public Health and \\ the Environment, P.O. Box 1, NL-3720 BA Bilthoven, The Netherlands
}

\begin{abstract}
Our objective in this study was to create a computer package which, when challenged by the structure of an organic molecule, will be able to predict the mechanism of its biodegradation in presence of anaerobic bacteria. A series of mechanistic models based on previous studies of the anaerobic biodegradation of organic molecules have been encoded into target/transform pairs. A total of 384 rules have been coded into a dictionary and made available to our META program. Endowed with this dictionary, the META program accurately predicts the mechanism of anaerobic degradation of molecules. Examples of the results obtained with the program are presented for benzoic acid, and polychlorinated nitrobenzenes. This program complements our previous derivation of equivalent mammal metabolism and aerobic biodegradation simulators.
\end{abstract}

\section{INTRODUCTION}

Biodegradation of Organic molecules in the Environment follows a number of paths. The most common mechanisms of degradation involve oxidations. These oxidations can take place as a result of the direct action of the oxygen in the air but, for organic substances, these oxidations are more often catalyzed by the enzymes of environmental microorganisms. Indeed, this "aerobic" biodegradation takes place as a result of ingestion by soil microbes. Ultraviolet light also contributes to the degradation process of chemicals left at the soil surface and hydrolysis plays some role in the process as well.

The propensity of molecules to be degraded by aerobic microbes has been extensively studied and the factors affecting degradability as well as the mechanism by which molecules are degraded have been discussed extensively in the literature (ref. 1). Our group (CWRU) has recently published a comprehensive study of this process, based on a theoretical evaluation of the functionalities that are conducing to biodegradability (ref. 1). The study was performed using the M-CASE program (ref. 2) to identify the substructural features of a molecule that are linked to biodegradability, and the META (ref. 3,4) program to translate these results into a mechanistic model of aerobic biodegradation. The combination of $\mathrm{M}$ CASE and META provides a predictive tool that can be used to predict the biodegradability potential (ref. 5) and probable mechanism of degradation for untested molecules.

Biodegradation under the surface or at the bottom of lakes and rivers usually cannot take place by aerobic biodegradation simply because the air is too rare for the aerobic microbes to survive. However, there are other microorganisms that survive under these conditions, which depend on the presence of water to breakdown molecules and provide nutrients (ref. 6). These "anaerobic" microbes have different digesting enzymes and their 
biodegrading action is quite different to that observed for the aerobic processes. The process is particularly important because it is the only process that can break down the otherwise persistent Polychlorinated Hydrocarbons that plague many sites. Relatively few studies have been made so far of this biodegradation process and very little is known about the mechanism by which they occur (ref. 7-8).

We have recently concluded a study of anaerobic biodegradability using the Multiple Computer Automated Structure Evaluator program, (M-CASE), to identify those substructures that appear to be the targets of the anaerobic degradating enzymes (ref. 9). This allowed us to identify a number of "attributes" that a molecule must possess in order to be a good candidate for anaerobic degradation.

In this study, we have translated this information into probable mechanistic concepts using the fragmentary knowledge of the products found in the biodegradation study of molecules containing these "attributes". These concepts were then entered into the META program, resulting in the creation of an expert system capable to predict the potential for a molecule to be biodegraded anaerobically and the mechanism and products that one expects to observe for that process.

\section{METHODOLOGIES}

The M-CASE program (sometimes referred to as CASE (ref. 6) or MULTICASE (ref. 2)) has been described in a number of previous publications (ref. 7, 8). It is an Artificial Intelligence program capable to uncover the molecular functionalities called "Biophores" that are responsible for an observed biological activity of molecules. It has already been used to uncover attributes of activity for a number of pharmacological endpoints such as antimycobacterium activity (ref. 9), capsaicin's activity (ref. 10), reversal of multidrug resistance (ref. 11) as well as to uncover attributes of toxic activity such as carcinogenicity (ref. 12), mutagenicity (ref. 13), teratogenicity (ref. 14) and many others.

The META program has also been described in the literature (ref. 4). META is an expert system drawing its knowledge from dictionaries of rules, created by experts on the bases of observations, chemical extrapolation of observations and knowledge derived from structure activity studies and artificial intelligence programs such as M-CASE. Prior to this work, two such dictionaries had been created and reported about in the literature (ref. 15, 16). One is a mammal metabolism dictionary, whose knowledge was drawn from a systematic evaluation of the known metabolizing enzymes and the products formed by the action of these enzymes. This study provided the impetus to create the META program which was then also outfitted with an aerobic metabolism dictionary based on an evaluation of the known mechanisms of aerobic biodegradation, supplemented by the knowledge brought about from a M-CASE study of the ease of biodegradation of known molecules.

Each of these dictionaries provides a quick graphical display of potential mechanisms of degradation of new chemicals. Neither of them however is meant to represent a single mammal or bacterial species, although this can and will probably be done in the future. Rather they provide a comprehensive set of possibilities that may be encountered, under varying relative concentrations, in different species.

\section{RESULTS AND DISCUSSION}

In a previous study we identified a number of substructures possibly targeted by the microorganism and responsible for the observed anaerobic degradation of 170 chemicals (ref. 9). The most significant of these "biophores" are the phenolic $\mathrm{OH}$ group, the $\mathrm{OH}$ or $\mathrm{SH}$ groups 
of aliphatic alcohols or thiols, the methoxy group in both aromatic and aliphatic compounds, the nitro group and so on.

The major anoxic pathways have been described in the literature (ref. 1, 6-8). Using that knowledge and our previous results, we suggest here some possible mechanistic pathways to explain the observed anaerobic degradation of the compounds containing any of these biophores.<smiles>O=C1CC(=O)CC(O)C1</smiles><smiles>Oc1cccc(O)c1</smiles><smiles>CC(=O)C/C=C\C(=O)O</smiles><smiles>CC(=O)CC(=O)CC(=O)OC(C)=O</smiles><smiles>CC(=O)CC(=O)CC(=O)OC(C)=O</smiles><smiles>C1CCCC1</smiles>

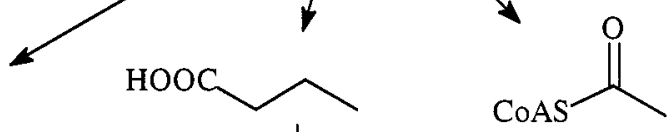<smiles>C=C(C)CC(C)=O</smiles>

COAS-OC

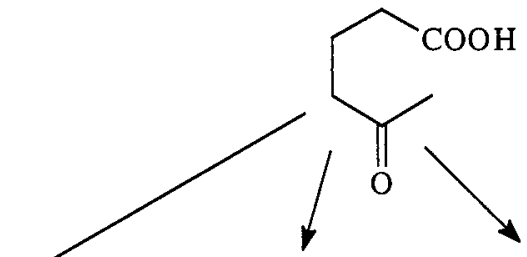<smiles>CC(=O)OCCCO</smiles>

CoAs

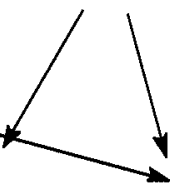<smiles>CCCC(C)C(C)=O</smiles><smiles>CC(=O)CCCCSC(C)=O</smiles>

Scheme 1: Central pathways leading from resorcinol and phloroglucinol to acetyl-CoA (ref. 1) 


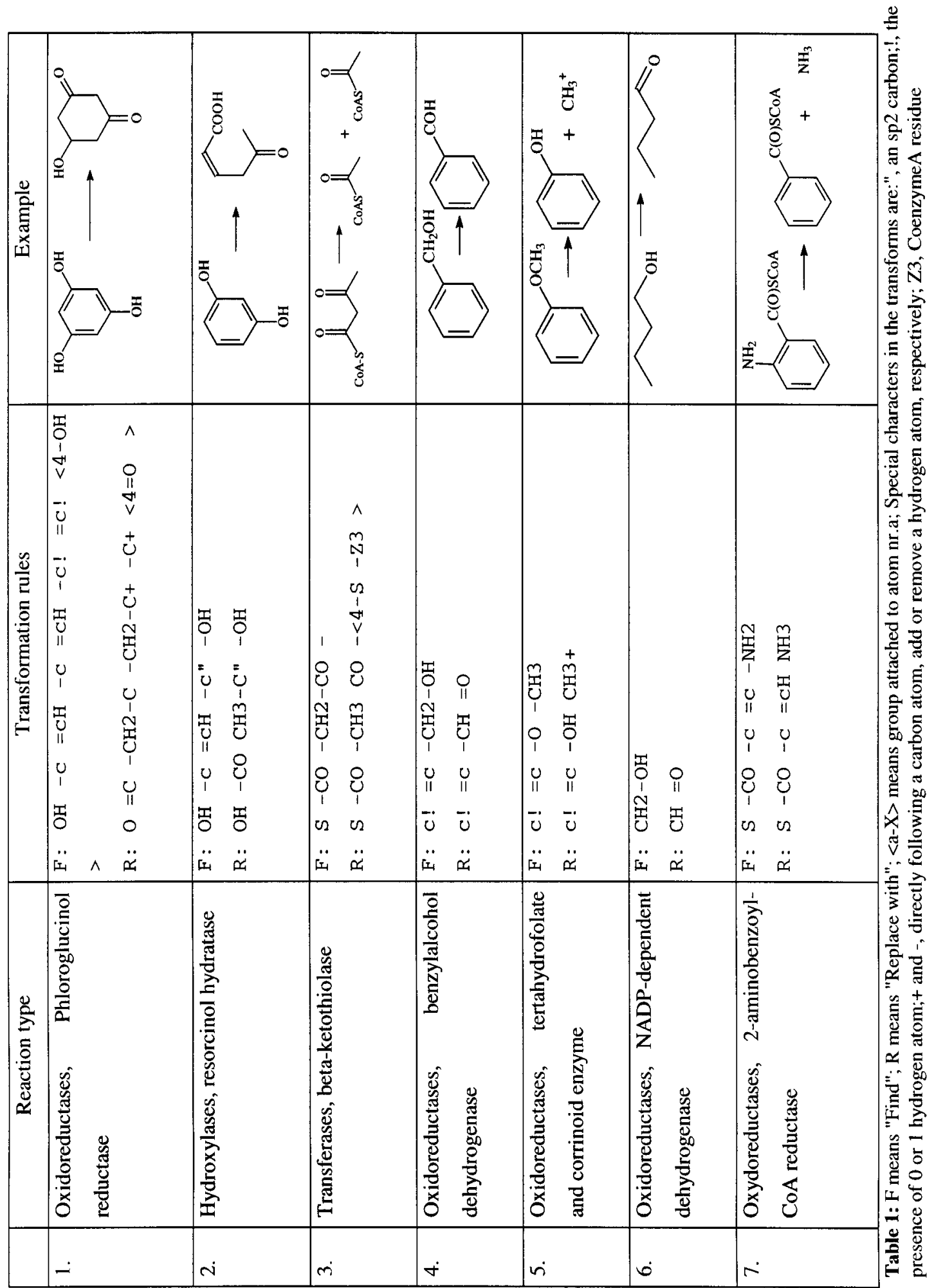




\section{The $\mathrm{OH}$ group in phenols}

Not surprisingly, we identified the phenol group as one of the major attributes of biodegradable molecules. Indeed, the phenolic $\mathrm{OH}$ group had previously been identified as one of the most important targets, leading to anaerobic biodegradation (ref. 1). Molecules such as polyphenols, phloroglucinol and resorcinol are central intermediates in the dearomatization pathway, leading to acetyl-CoA adducts and subsequently to $\mathrm{CO}_{2}$. According to the literature (ref. 1) and based on common chemical sense, these pathways can be described as shown in Scheme 1. As can be seen from this scheme, the central pathway for polyphenols can be subdivided into several processes: cycle reduction by some reductases, aliphatic cycle cleavage by hydrolases, $\mathrm{OH}$ oxidation by dehydrogenases and beta-oxidation by beta ketothiolases. We have coded all these transformation into target/transform rules used by the META program (ref. 4) to identify metabolism transforms. Some examples of such transforms are shown in Table 1.<smiles>CC(=O)OC(=O)c1ccc([IH]c2ccc(C(=O)O)cc2)c(C(=O)O)c1</smiles>

A<smiles>CC(=O)c1ccc(-c2cccc(C(=O)O)c2)cc1</smiles>

B

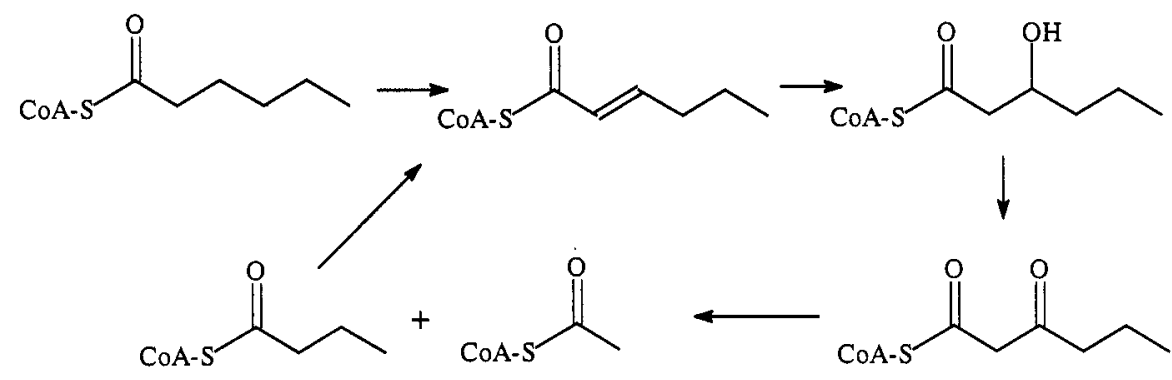

C

Scheme 2: Possible applicatiom of aliphatic $\mathrm{OH}$ oxidation transform (ref. 1). A.Benzylic alcohol degradation. B. Degradation of the side aliphatic chain in aromatic compounds. C. Beta-oxidation cycle

\section{The $\mathrm{OH}$ group in aliphatic alcohols}

Anaerobic degradation initiated at the $\mathrm{OH}$ group of aliphatic alcohols is a major component of the anoxic pathway for degradation of various types of compounds (ref. 1) such as benzylic alcohol and other alkyl side chains in aromatic compounds. It also is a important component of the central anaerobic pathway for aromatic compounds (See Scheme 1). as well as a major component of the beta-oxidation cycle (Scheme 2). The alcohol is believed to be oxidized into 
an aldehyde (ref. 6) and the corresponding transformation reaction was implemented in our dictionary as a universal transform. This is shown in Table 1 as entry nr. 6 .

\section{The Methoxy group in aromatic and aliphatic moieties}

The methoxy-substituent was recognized (ref. 9) as significant to the inception of anaerobic biodegradation of molecules containing it. Indeed all compounds containing this biophore are found to be readily biodegraded under anaerobic conditions. The process is believed to consist of an initial de-methylation, which is particularly prevalent in aromatic compounds (ref. 1). The chemically inert methoxy group is not normally a target for bacterial transformation under aerobic conditions but can be de-methylated by the enzymatic machinery of such acetogenic bacteria as Acetobacterium (ref. 21), Clostridium (ref. 22), S.ovata (ref. 23) A.woodi (ref. 24) and a few others. It was demonstrated (ref. 23) that O-demethylation proceeds via formation of methyl derivatives of tetrahydrofolate by a corrinoid enzyme (ref. 24)

$$
\text { Ar-O- } \mathrm{CH}_{3}+\mathrm{H}_{4} \text { folate } \rightarrow \text { Ar- } \mathrm{OH}+\mathrm{H}_{4} \text { folate- } \mathrm{CH}_{3}
$$

Subsequent degradation will usually occur at the newly formed phenol. This peripheral metabolic reaction was implemented as transform 5 in Table 1.

It is also commonly observed that even in aliphatic compounds the metoxy-group can sometimes be de-methylated under anaerobic conditions to yield the subsequent alcohol (ref. $25)$. This reaction has therefore also been implemented as a transform in the dictionary.

\section{Missed transformations}

Because of the limited number of compounds in the anaerobic degradation database used for our prior study (ref. 9) some important transformations were probably missed. We therefore went to the literature to identify possible biodegradation pathways for other functionalities. In this way we identified additional transformations such as the activation of aromatic acids by coenzyme A ligases (ref. 26), carboxylation of phenolic and anilinic compounds by phenolkinaze and phenylphosphate hydrolase (ref. 27), reductive dehydroxylation by hydroxybenzoyl-CoA reductase (ref. 28), reductive deamination (ref. 29), reductive dehalogenation by dehalogenases (ref. 30), alpha-oxidation of carboxymethyl group (ref. 31), methyl oxidation by methylhydroxilation (ref. 32), transhydroxylation by transhydroxylase (ref. 33) and decarboxylation by decarboxylases (ref. 34). Transformation rules reflecting these literature data were also incorporated into our dictionary. The final dictionary was completed by a number of chemically driven low rate spontaneous reactions and contains a total of 336 transformation rules divided into 9 different activity classes, i.e. slow spontaneous reactions, oxidoreductases, synthases, decarboxylases, transferases, hydrolases, carboxylases, coenzyme-A lidases and cyclic anaerobic processes. Some of the resulting transforms are shown in Table 1.

In its current state, the rules were designed to be as general as possible. The META program outfitted with the dictionary was then tested to evaluate its ability to predict the possible products of anaerobic degradation of a wide variety of molecules. Some of these tests are presented in the next section. As will be seen, the results are encouraging.

\section{The central benzoyl-CoA pathway of anaerobic degradation}

This mechanism is considered to be one of most important pathways of anaerobic degradation of aromatic compounds. The benzoyl-CoA is the most commonly observed intermediate in the biodegradation of aromatic compounds (ref. 1). Its reduction leads directly to acetyl-CoA, which is normally oxidized via the citric acid cycle, ultimately producing $\mathrm{CO}_{2}$. We believe that an accurate description of this main degradation route is essential for our methodology to be credible. The results of the analyses of the biodegradation of benzoic acid is shown in Scheme 3 . 


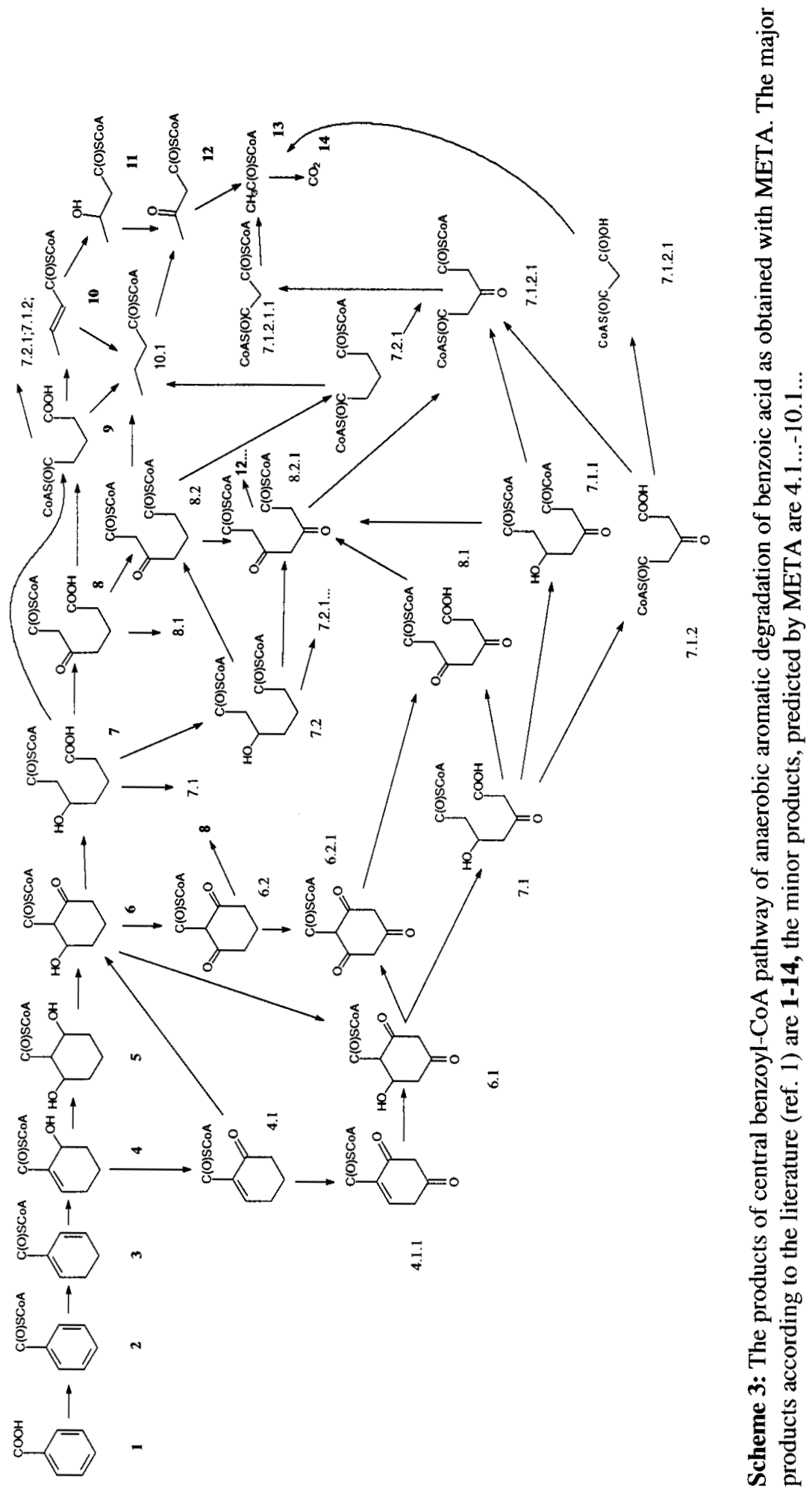




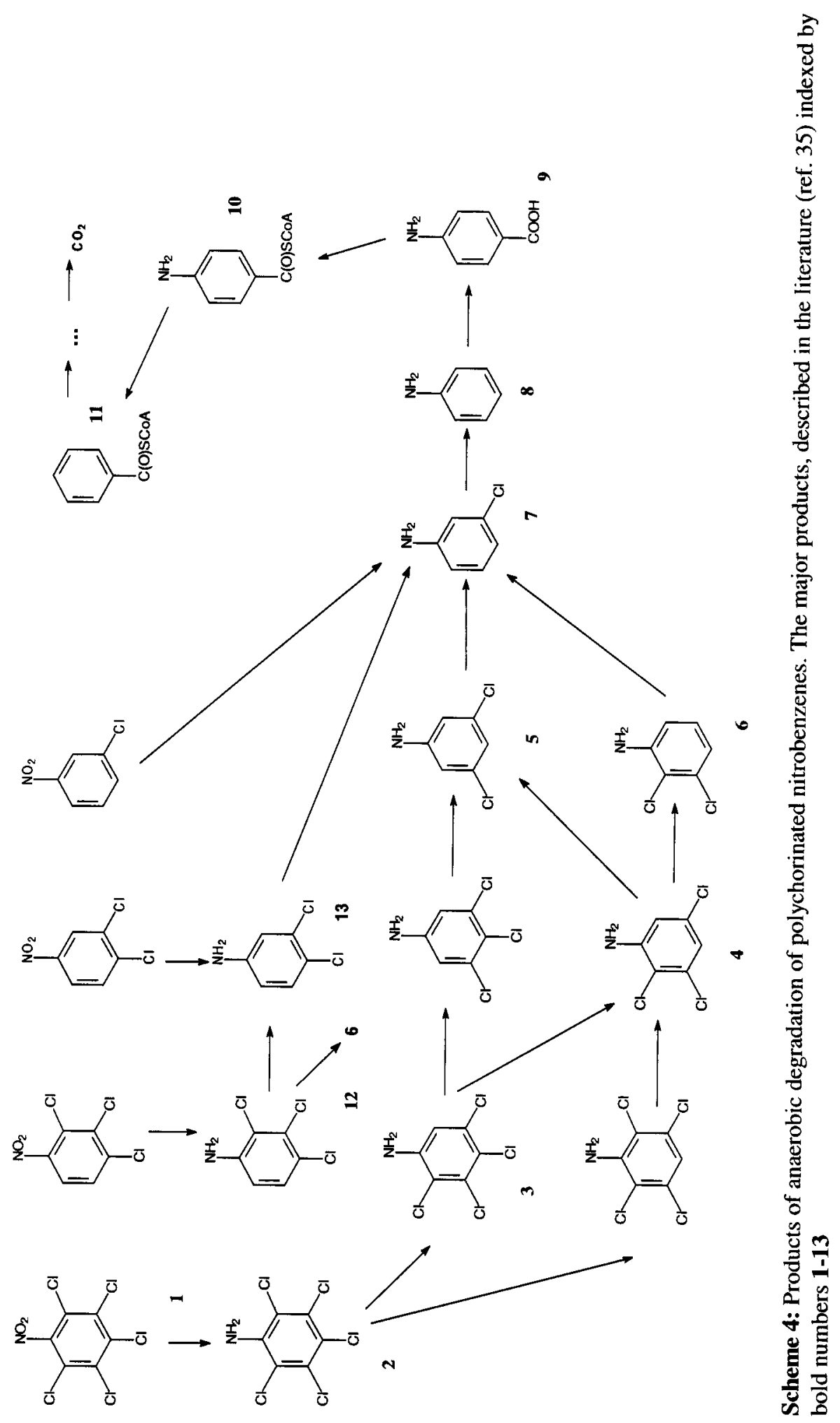


As can be seen from the metabolic tree of Scheme 3, META successfully reproduced the main pathway going from benzoic acid 1 to $\mathrm{CO}_{2} 14$. All products, indexed by bold number (like 1,2 etc) are the products of this main pathway. However, META also predicted a number of additional products and reactions, indexed as 4.1, 6.1 etc. All these products and reaction seem to be reasonable and can be considered as possible intermediates or trace products of side reactions. All of them are leading to various acetyl-CoA adducts.

\section{The anaerobic degradation of polychlorinated nitrobenzenes}

Polychlorinated aromatic compounds are widely distributed in the biosphere mainly due to man's carelesness (ref. 7). These compounds are causing major concern because of their persistence under aerobic conditions. Their toxicity and recalcitrance are attributed to the presence of the halogens, and the degree of recalcitrance depends on the number and location of the halogen substituents.

We have chosen as examples of the application of our program to the anaerobic degradation of polychlorinated nitrobenzenes, four cases which are well documented in the literature (ref. 35). Scheme 4 shows the results when META was used to evaluate the biodegradation products of pentachloronitrobenzene, 2,3,4 -tricholonitrobenzene, 3,4dichloronitrobenzene and 3-chloronitrobenzene.

As can be seen from this metabolic tree, the META results are practically the same as the observed ones, described in the literature (ref. 35). The reduction of the nitro group proceeds with $100 \%$ yield for all four starting compounds, which is in good agreement with the literature data (ref. 35). The removal of chlorine atoms proceeds by successive reductive dechlorination reaction. This has indeed been found for a number of bacteria in lake sediments and sewage sludge (ref. 7). The chlorine atoms, attached to the ortho-position of the aniline ring, are more readily removed than those in the para-position. For all initial molecules the last chlorinated product is meta-chloroaniline. After dechlorination of the last chlorine atom, aniline 8 is carboxylated by p-amino carboxylase (ref. 1), leading to para-aminobenzoic acid 9, which then biodegrades as is usual for benzoate derivatives - via activation by coenzyme A (from $\mathbf{1 0}$ to 11) leading eventually to $\mathrm{CO}_{2}$. This is shown in Scheme 3.

The META program produced some additional products of the anaerobic degradation, but they all appear as intermediates in the reactions leading to the indicated main products.

\section{CONCLUSION}

On the basis of the results of our previous investigation and a thorough survey of the literature, a dictionary of rules for anaerobic degradation of organic compounds was created. At this time, the dictionary contains 384 rules. Using this dictionary within the context of the META program, we were able to reproduce the central benzoyl-CoA pathway for the anaerobic degradation of aromatic compounds, and all main degradation products of a family of polychlorinated nitrobenzenes. Some additional products were predicted in each case, but all of them lie within on the main pathways of degradation and can be considered as intermediates or minor products.

Based on a comparison between our results and literature data, it is clear that the META methodology with its new dictionary is able to predict correctly the main products of anaerobic degradation of at least a number of substituted aromatic compounds. After further compilation of the literature data, we expect to be able to create additional rules which, when included in the dictionary will allow the program to predict the pathways of anaerobic metabolism even of an even wider variety of compounds. 


\section{REFERENCES}

1. J. Heider, G. Fuchs. Eur. J. Biochem. 243, 577-596 (1997).

2. G. Klopman, M. Tu. Environ. Toxicol. Chem. 16, 1829-1835 (1997).

3. G. Klopman. Quanti. Struct.-Act. Relat. 11, 176-184 (1992).

4. G. Klopman, M. Dimayuga, J. Talafous. J. Chem. Inf. Comput. Sci. 34, 1320-1325 (1994).

5. G. Klopman. In Biodegradability Predictions, (W.J.G.M. Peijnenburg, J. Damborsky, eds.). pp. 27-40. Kluwer Academic Publishers, Dordrecht (1996).

6. W.C. Evans. Nature 270, 17-22, (1972).

7. D.J. Hardman. Crit.Rev.Biotech. 11, 1-40 (1991).

8. D.A. Abramowic. Envon. Health Perspect. 103, $97-99$ (1995).

9. E. Rorije, W.J.G.M. Peijnenburg, G. Klopman. Environ. Toxicol. Chem. (1998) in press.

10. G. Klopman, J. Am. Chem. Soc. 106, 7315-7320 (1984).

11. H.S. Rosenkranz, G. Klopman. Toxicol. Ind. Health 4, 533-540 (1988).

12. G. Klopman, D.M. Balthasar, H.S. Rosenkranz. Environ. Toxicol. Chem. 12, 231-240 (1993).

13. G. Klopman, S. Wang, M.R. Jacobs, J.J. Ellner. Antimicrobial Agents and Chemotherapy 37, 1807-1815 (1993).

14. G. Klopman, J.-Y. Li. J. Computer-Aided Molecular design 9, 283-294 (1995).

15. G. Klopman, L.M. Shi, A. Ramu. Pharmacology 52, 323-334 (1997).

16. G. Klopman, H.S. Rosenkranz. Environ. Health Perspect. 96, 67-75 (1991).

17. G. Klopman, M.R. Frierson, H.S. Rosenkranz. Mutation Res. 228, 1-50 (1990).

18. G. Klopman, M. Dimayuga. J. Computer-Aided Molecular Design 4, 117-130 (1990).

19. G. Klopman, Y.P. Zhang, D.M. Balthasar, H.S. Rosenkranz. Environ. Toxicol. Chem. 14, 395-403 (1995).

20. H.S. Rosenkranz, Y.P. Zhang, G. Klopman. In Modulation of Cellular Responses in Toxicity, (C.L. Galli, A.M. Goldberg, M. Marinovich, eds.), NATO Cell Biology Series, Volume 93. pp. 91-123. Springer, Berlin/New York (1995).

21. R. Bache, N. Pfennig. Arch. Microbiol. 130, 255-261 (1981).

22. K.A. DeWeerd, A. Saxena, D.P. Nagle, J.M. Suflita. App. Env. Microbiol. 54, 1237-1242 (1988).

23. M.H. Berman, A.C. Frazer. App. Env. Microbiol. 58, 925-931 (1992).

24. E. Stupperich, R. Konle. App. Env. Microbiol. 59, 3110-3116 (1993).

25. G. Fuchs, M.E.S. Mohamed, U. Altenschmidt, J. Koch, A. Lack, R. Brackman, C. Lochmeyer, B. Oswald. In Biochemistry of Microbal Degradation (C. Ratledge, ed.), pp.513-553. Kluwer Academic Publishers, Dordrecht (1994).

26. U. Altenschmidt, B. Oswald, G. Fuchs. J. Bacteriol. 173, 5494-5501 (1991).

27. A. Lack, I. Tommasi, M. Aresta, G. Fuchs. Eur. J. Biochem. 197, 473-479 (1991).

28. R. Brackmann, G. Fuchs. Eur. J. Biochem. 213, 563-571 (1993).

29. S. Schnell, B. Schink. Arch. Microbiol. 158, 183-190 (1992).

30. S. Ni, J.K. Frederikson, L. Xun. J. Bacteriol. 177, 5135-5139 (1995).

31. M.E. Mohamed, G. Fuchs. Arch. Microbiol. 159, 563-573 (1993).

32. D.J. Hopper, I.D. Bossert, M.E. Rhodes-Roberts. J. Bacteriol. 173, 1298-1301 (1991).

33. A. Brune, S. Scnell, B. Schink. Appl. Env. Microbiol. 58, 1861-1868 (1992).

34. Z. He, J. Wiegel. J. Bacteriol. 178, 3539-3543 (1996).

35. S. Susarla, S. Masunaga, Y. Yonezawa. Chemosphere 32, 967-977 (1996). 